\title{
Respiratory mechanics in ventilated COPD patients: forced oscillation versus occlusion techniques
}

\author{
R. Farré*, M. Ferrer+, M. Rotger*, A. Torres+, D. Navajas*
}

Respiratory mechanics in ventilated COPD patients: forced oscillation versus occlusion techniques. R. Farré, M. Ferrer, M. Rotger, A. Torres, D. Navajas. CERS Journals Ltd 1998.

ABSTRACT: The respiratory mechanics of artificially ventilated chronic obstructive pulmonary disease (COPD) patients were investigated by means of the forced oscillation (FOT) and the end-inspiratory airway occlusion (AOT) techniques.

FOT was applied to measure respiratory resistance $(R \mathrm{rs})$ and reactance $(X \mathrm{rs})$ from $0.25-16$ Hz. Maximum $\left(R_{\max }\right)$ and minimum $\left(R_{\min }\right)$ resistances, static elastance $\left(E_{\mathrm{st}}\right)$ and time constant $(\tau)$ were computed by AOT. FOT and AOT data were interpreted with models featuring airway wall shunt, tissue viscoelasticity and parallel inhomogeneity. $R \mathrm{rs}^{*}$ and $X_{\mathrm{rs}} *$, predicted from the AOT data, were computed and compared with $R$ rs and $X$ rs measured by FOT.

$R$ rs and $X$ rs $\left(\mathrm{hPa} \cdot \mathrm{s}^{\cdot} \mathrm{L}^{-1}\right)$ decreased from $31.2 \pm 10.3$ to $5.9 \pm 4.6$ and increased from $-20.3 \pm 7.1$ to $-8.0 \pm 4.4$ from $0.25-16 \mathrm{~Hz}$, respectively. Central resistance $(R \mathrm{c})$ and peripheral resistance $\left(R_{\mathrm{p}}\right)$ (in hPa:s$\left.\cdot \mathrm{L}^{-1}\right)$, and shunt elastance $\left(E_{\text {sh }}\right)$ and tissue elastance $\left(E_{t}\right)$ (in $h P a \cdot L^{-1}$ ) were $4.4 \pm 5.4,28.4 \pm 15.3,723 \pm 393$ and $31.8 \pm 10.1$, respectively. $R$ min, $R$ max and $E$ st were $18.4 \pm 5.9,28.4 \pm 12.8$ and $18.1 \pm 4.2$ respectively, and $\tau=0.76 \pm 0.25 \mathrm{~s}$. The frequency dependence of predicted $R \mathrm{rs}^{*}$ and $X_{\mathrm{rs}} *$ differed markedly from that of measured $R$ rs and $X$ rs.

The use of different models to interpret the measured data suggests that both airway and tissue properties determined the frequency dependence of respiratory resistance and respiratory reactance in ventilated chronic obstructive pulmonary disease patients at the investigated frequencies $(0.25-16 \mathrm{~Hz})$. Eur Respir J 1998; 12: 170-176.
*Laboratory Biofisica i Bioenginyeria, Facultat de Medicina, IDIBAPS, Universitat de Barcelona, Spain. ${ }^{+}$Servei de Pneumologia, Hospital Clinic Provincial de Barcelona, IDIBAPS, Barcelona, Spain.

Correspondence: R. Farré

Laboratory Biofisica i Bioenginyeria Facultat de Medicina

Casanova 143

E-08036 Barcelona

Spain

Fax: 3434035260

Keywords: Airway resistance

frequency dependence

lung inhomogeneity

monitoring

respiratory impedance viscoelasticity

Received: July 281997

Accepted after revision March 131998

This work was supported in part by Comisión Interministerial de Ciencia y Tecnología (CICYT, SAF96-0076)
Optimization of the ventilator settings in mechanical ventilation is a key issue in minimizing the risk of barotrauma and haemodynamic compromise, in avoiding hyperinflation and in reducing the work of breathing [1]. Improvement in the ventilator variables may be facilitated by better understanding of the role played by the different mechanical properties of airways and tissue in determining the dynamic relationships among the pressure, flow and volume excursions applied to the patient's respiratory system $[2,3]$. The use of a mechanical model to mimic respiratory mechanics as realistically as possible for each pathological situation may be helpful in predicting the outcome variables of clinical interest in response to the applied ventilator waveform. In the case of mechanically ventilated chronic obstructive pulmonary disease (COPD) patients, the conventional simple model consisting of a resistance and an elastance is not able to describe adequately the behaviour of the respiratory system [4]. In these patients, respiratory mechanics has been interpreted in terms of the viscoelastic tissue properties and/or the gas redistribution phenomena due to airways inhomogeneity [5-7].

Published works devoted to analysing in detail the dynamic response of the respiratory system in artificially ventilated COPD patients report conflicting results. Indeed, when the technique of end-inspiratory airway occlusion with a constant flow inflation was applied, the effective resistance and elastance of the respiratory system could be interpreted in terms of a homogeneous resistance and a viscoelastic tissue compartment [5]. By contrast, data obtained by means of the forced oscillation technique (FOT) in COPD patients suggested that airway inhomogeneity plays a major role in determining the frequency dependence of respiratory resistance and reactance over a wide frequency range [7]. Nevertheless, it is difficult to compare the results from these works since the two techniques applied differ in both the frequency domain and the amplitude range of excursions and were applied to patients with possibly different degrees of COPD. Therefore, the aim of this work was to characterize better the mechanics of the respiratory system in artificially ventilated COPD patients by applying the FOT and the end-inspiratory airway occlusion technique (AOT) to the same patients. A key point in making the comparison between the two techniques was to extend the FOT measurements to the low frequencies typical of the occlusion technique. To this end, a modified FOT device [8] was used which, in contrast to the set-ups used in previous measurements in mechanically ventilated patients [7, 9], allowed FOT to be applied for frequencies down to $0.25 \mathrm{~Hz}$. The results obtained by means of both techniques were interpreted in terms of models featuring tissue and airway properties. 


\section{Subjects and methods}

The study was conducted on five (four males and one female) COPD patients who were admitted to the respiratory intensive care unit (ICU) of the hospital owing to an acute exacerbation of their underlying disease. The COPD diagnosis was established according to the forced expiration indices determined after or before the admission of the patient into the ICU. The study protocol was approved by the Ethics Committee of the hospital and informed consent was obtained from the next of kin of the patients. The study was carried out $12-36 \mathrm{~h}$ after the admission of the patient to the ICU. The patients, in a supine position and intubated with a cuffed orotracheal tube $(8 \mathrm{~mm}$ internal diameter (ID)), were mechanically ventilated with a Siemens Servoventilator 900-C (Siemens, Solna, Sweden) in the constant flow volume-controlled mode. The ventilator settings (table 1) were established by the attending physician. To carry out the study, which lasted for $\sim 20$ min, the patients were sedated (i.v. infusion of 5-10 mg of midazolam, Dormicum ${ }^{\circledR}$; Roche SA, Madrid, Spain) and paralysed (i.v. infusion of $2 \mathrm{mg}$ of pancuronium bromide, Pavulon $\AA ;$ Orgenon-Hermes SA, Sant Boi de Llobregat, Spain). At the start of the study, tracheal secretions were conventionally aspirated and external positive end-expiratory pressure (PEEP), if any, was removed. The inflating pressure of the endotracheal tube cuff was checked periodically and care was taken to avoid leaks in the connections.

Flow was measured by means of a heated Fleisch-II type pneumotachograph (Metabo, Epalinges, Switzerland) placed between the Y-piece of the ventilator and the endotracheal tube. The pressure drop across the pneumotachograph was recorded with a differential transducer $( \pm 2$ hPa, LCVR; Celesco, Canoga Park, CA, USA). Tracheal pressure was measured with a piezo-resistive pressure transducer (176PC/14; Honeywell, Freeport, IL, USA) connected to a catheter $(50 \mathrm{~cm}$ in length and $0.12 \mathrm{~cm}$ ID) with a lateral pressure port at its tip placed $2 \mathrm{~cm}$ beyond the outlet of the endotracheal tube [10]. This catheter was periodically cleaned by injecting a bolus of $3 \mathrm{~mL}$ of air through it. Pressure and flow signals were low-pass filtered (Butterworth, eight poles, $32 \mathrm{~Hz}$ ), sampled at 128 $\mathrm{Hz}$ and stored in a microcomputer. A FOT generator especially designed for low-frequency measurements in mechanically ventilated patients [8] was placed in parallel with the ventilator in the inspiratory line. The FOT generator was connected to the inspiratory line by means of a flexible tube $(2 \mathrm{~mm} \mathrm{ID,} 80 \mathrm{~cm})$ and a Y-valve. This valve, which was closed during the normal ventilator cycling, was connected directly to the Y-piece to increase minim-

Table 1. - Ventilation parameters

\begin{tabular}{|c|c|c|c|c|c|c|}
\hline $\begin{array}{l}\text { Patient } \\
\text { No. } \\
\end{array}$ & $\begin{array}{c}f \mathrm{~B} \\
\text { beats } \mathrm{min}^{-1}\end{array}$ & $\begin{array}{l}t \mathrm{I} \\
\mathrm{s} \\
\end{array}$ & $\begin{array}{l}V_{\mathrm{T}} \\
\mathrm{L} \\
\end{array}$ & $\begin{array}{c}V^{\prime} \\
\mathrm{L} \cdot \mathrm{S}^{-1} \\
\end{array}$ & $F \mathrm{I}, \mathrm{O}_{2}$ & $\begin{array}{c}\mathrm{PEEPi} \\
\mathrm{hPa}\end{array}$ \\
\hline 1 & 11.2 & 1.29 & 0.512 & 0.397 & 0.40 & 10.6 \\
\hline 2 & 11.3 & 1.37 & 0.423 & 0.308 & 0.30 & 10.9 \\
\hline 3 & 15.0 & 0.95 & 0.539 & 0.567 & 0.35 & 10.3 \\
\hline 4 & 11.2 & 1.15 & 0.556 & 0.483 & 0.40 & 10.1 \\
\hline 5 & 11.3 & 1.33 & 0.589 & 0.443 & 0.32 & 10.8 \\
\hline Mean & 12.0 & 1.22 & 0.524 & 0.440 & 0.35 & 10.5 \\
\hline SD & 1.7 & 0.17 & 0.063 & 0.097 & 0.05 & 0.3 \\
\hline
\end{tabular}

fB: ventilator frequency; $t \mathrm{I}$ : inspiratory time; $V \mathrm{~T}$ : tidal volume; $V^{\prime}$ : constant flow inflation; $F \mathrm{I}, \mathrm{O}_{2}$ : oxygen inspiratory fraction; PEEPi: intrinsic positive end-expiratory pressure. ally the air volume, and hence the compliance, in the ventilation line when the valve was closed. The compliance of the system connecting the ventilator to the patient was decreased by omitting the humidifier and reducing the length of the standard low-compliance tubing of the ventilator $(2$ $\mathrm{cm} \mathrm{ID,} 60 \mathrm{~cm}$ ) [5]. Four end-inspiratory occlusion manoeuvres and four FOT measurements were carried out in a random order in each patient, allowing at least 10 normal ventilation cycles between measurements.

To measure respiratory system resistance $(R \mathrm{rs})$ and reactance $(X \mathrm{rs})$ by FOT the expiratory valve of the ventilator was occluded by pressing the corresponding button and the valve connecting the FOT generator to the patient was manually opened. The forced oscillation signal $( \pm 3 \mathrm{hPa}$, $\left.\pm 80 \mathrm{~mL} \cdot \mathrm{s}^{-1}\right)$ contained power at $0.25,0.5,1,2,4,8$ and 16 $\mathrm{Hz}$ and the amplitudes of the low-frequency components were enhanced. FOT was applied for $\sim 12 \mathrm{~s}$ of end-expiratory pause at the intrinsic PEEP (PEEPi) corresponding to the ventilator settings in each patient (table 1). After application of FOT the normal ventilator cycle was resumed. Rrs and $X$ rs were computed from the last $8 \mathrm{~s}$ of the recorded pressure and flow. These signals were divided into three blocks of $4 \mathrm{~s}$ each (50\% overlapping). After subtraction of the mean value, each block was multiplied by a Hanning window and its fast Fourier transform (FFT) was computed. $R$ rs and $X$ rs were computed by averaging in the frequency domain ( 12 blocks) the data from the four FOT measurements. The frequency responses of the pressure and flow measuring systems were digitally corrected.

The end-inspiratory occlusion manoeuvre was applied first by pushing $(\sim 3 \mathrm{~s})$ the end-expiratory button of the ventilator to reach PEEPi, then by releasing the hold button to allow for the inspiratory inflation and then by pressing the end-inspiratory pause button for $\sim 6 \mathrm{~s}$ before resuming normal ventilation [5, 11-13]. For each occlusion manoeuvre the closing time was defined as the time at which flow decreased by $50 \%$. The four occlusion manoeuvres in each patient were averaged after being synchronized in accordance with the closing time. The effect of the finite closure time of the ventilator valve was reduced as suggested [14]. Pressure immediately before flow interruption $(P 1)$ was determined by extrapolating the preocclusion increasing pressure to the closing time. Pressure immediately after flow interruption $\left(P_{2}\right)$ was determined by backextrapolation of the postocclusion decreasing pressure to the closing time. The plateau pressure at $3 \mathrm{~s}$ after the occlusion $\left(P_{3}\right)$ and the time constant $(\tau)$ of the pressure relaxation immediately after the flow interruption were computed. The resistances and elastances commonly used to characterize the occlusion manoeuvre were computed as $R \min =(P 1-P 2) / V^{\prime}, R \max =(P 1-P 3) / V^{\prime}, E_{\mathrm{st}}=\left(P_{3}-\right.$ $\mathrm{PEEPi}) / V \mathrm{~T}$ and $\Delta E=(P 2-P 1) V \mathrm{~T}[5,11-13]$, where $R \min =$ minimum resistance, $R \max =$ maximum resistance, $V^{\prime}=$ gas flow, $E$ st $=$ static elastance, $V \mathrm{~T}=$ tidal volume, and $\Delta E$ $=$ differences in elastance.

Data measured by FOT and by the occlusion technique were interpreted in terms of the models A, B and C in figure 1 . Model A, which was initially proposed by MEAD [15] and recently used to interpret FOT data in ventilat- ed COPD patients [7], consists of a central resistance $(R \mathrm{c})$, a shunt elastance $(E s h)$ accounting for airway wall compliance, a peripheral resistance $(R \mathrm{p})$ and a tissue elastance $(E \mathrm{t})$. Model B, usually employed to interpret respiratory 
A

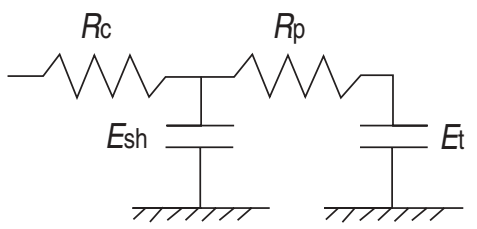

B

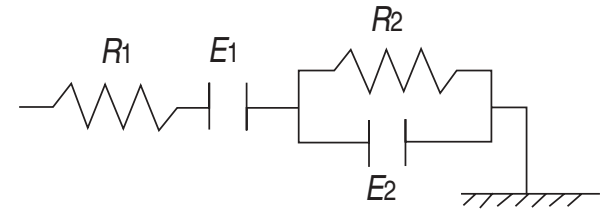

C

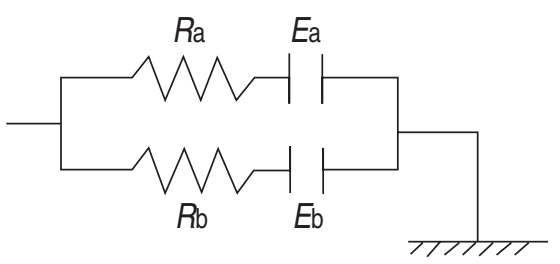

D

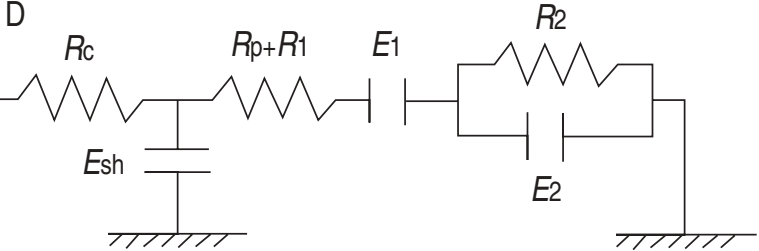

Fig. 1. - Mechanical models to interpret data measured by the forced oscillation and airway occlusion techniques. A: Central $(R \mathrm{c})$ and peripheral $(R \mathrm{p})$ airway resistances, shunt $(E \mathrm{sh})$ and tissue $(E \mathrm{t})$ elastances. B: Airway resistance $(R 1)$ and viscoelastic tissue compartment $(E 1, R 2, E 2)$. C: Inhomogeneous parallel $(R \mathrm{a}-E \mathrm{a}$ and $R \mathrm{~b}-E \mathrm{~b})$ pathways. D: Central $(R \mathrm{c})$ and peripheral $(R \mathrm{p})$ airway resistances, airway shunt elastance $(E \mathrm{sh})$, Newtonian tissue resistance $(R 1)$ and viscoelastic tissue compartment $(E 1, R 2, E 2)$.

system mechanics by means of the occlusion technique [16], consists of an airway resistance $(R 1)$ and a viscoelastic compartment of the respiratory tissues $\left(R 2, E_{1}\right.$ and $\left.E_{2}\right)$. Model C corresponds to a respiratory system inhomogeneity characterized by two parallel resistance-elastance $(R \mathrm{a}-E \mathrm{a}, R \mathrm{~b}-E \mathrm{~b})$ pathways. The concept of parallel inhomogeneity was initially proposed by Oтьs $e t$ al. [17] and has more recently been employed to interpret the frequency dependence of resistance and elastance [18-20]. As these models (A, B and C) are described by the same general equation of motion, they exhibit the same frequency dependence of resistance and reactance and the same response when subjected to the occlusion manoeuvre $[6,21]$. Consequently, the parameters of one of the models can be computed from the parameters of any of the other models. $R$ rs and $X$ rs measured by FOT were used to compute the $R \mathrm{c}, E \mathrm{sh}, R \mathrm{p}$ and $E \mathrm{t}$ of model A by minimizing the distance ( $\varepsilon$ ) between the model and the data [7] for positive values of the parameters. $R 1, E 1, R 2$ and $E 2$ of model B and $R$ a, $E \mathrm{a}, R \mathrm{~b}$ and $E \mathrm{~b}$ of model $\mathrm{C}$ were computed from the parameters derived from model A. The data obtained by the occlusion technique were used to compute the parameters $R 1, R 2, E 1$ and $E 2$ of model B $(R 1=R \min , E 1=E \mathrm{st}, R 2=$ $(R \max -R \min ) /(1-\exp (-t \mathrm{t} / \tau))$ and $E 2=R 2 / \tau[5,11-13,21-23])$ and these values were used to compute $R \mathrm{c}, E \mathrm{sh}, R \mathrm{p}$ and $E \mathrm{t}$ of model $\mathrm{A}$ and $R \mathrm{a}, E \mathrm{a}, R \mathrm{~b}$ and $E \mathrm{~b}$ of model $\mathrm{C}$. The frequency dependence of respiratory resistance $\left(R \mathrm{r}{ }^{*}\right)$ and reactance $\left(\mathrm{Xrs}^{*}\right)$ estimated for each patient from the occ- lusion technique was computed $\left(R \mathrm{rs} *=R 1+R 2 /\left(1+(2 \pi f \tau)^{2}\right)\right.$ and $\left.X \mathrm{rs}^{*}=E \mathrm{st}-2 \pi f \tau^{2} E 2 /\left(1+(2 \pi f \tau)^{2}\right)[21]\right)$.

In addition to the simple models A, B and C, Rrs, and $X \mathrm{rs}$, measured by FOT were interpreted by a more general model (fig. 1D) which includes compliant airways and a viscoelastic tissue compartment. The airway compartment consisted of $R \mathrm{c}$ and $R$ p separated by $E_{\mathrm{sh}}$, as in model A. The tissue compartment was characterized by a Newtonian tissue resistance $(R 1)$, an elastance $(E 1)$ and an element with a time constant $\left(R_{2} / E 2\right)$, as in model $\mathrm{B}$. In this model, $R 1$ and $R$ p play the same role in determining its mechanical properties and are, therefore, indistinguishable.

\section{Results}

Figure 2a plots the $R$ rs and $X$ rs from $0.25-16 \mathrm{~Hz}$ measured by FOT in a representative patient (no. 1). Figure 3a shows that, on average, Rrs (mean \pm SE) decreased progressively over the frequency bands from $31.2 \pm 4.6 \mathrm{hPa} \cdot \mathrm{s} \cdot \mathrm{L}^{-1}$ at $0.25 \mathrm{~Hz}$ to $5.9 \pm 2.1 \mathrm{hPa} \cdot \mathrm{s} \cdot \mathrm{L}^{-1}$ at $16 \mathrm{~Hz}$. $\mathrm{X}_{\mathrm{rs}}(\mathrm{mean} \pm \mathrm{sE}$ ) increased markedly from $-20.3 \pm 3.2 \mathrm{hPa} \cdot \mathrm{s} \cdot \mathrm{L}^{-1}$ at $0.25 \mathrm{~Hz}$ to $-10.1 \pm 1.8 \mathrm{hPa} \cdot \mathrm{s} \cdot \mathrm{L}^{-1}$ at $2 \mathrm{~Hz}$ and from then on slightly increased to $-8.0 \pm 2.0 \mathrm{hPa} \cdot \mathrm{s} \cdot \mathrm{L}^{-1}$ at $16 \mathrm{~Hz}$. Respiratory elastance $(E \mathrm{rs} ; E \mathrm{rs}=-2 \pi f \cdot X \mathrm{rs})$ increased progressively with frequency in all patients (fig. 4). The use of models A, $\mathrm{B}$ and $\mathrm{C}$ to interpret the measured $R \mathrm{rs}$ and $\mathrm{Xrs}$ resulted in
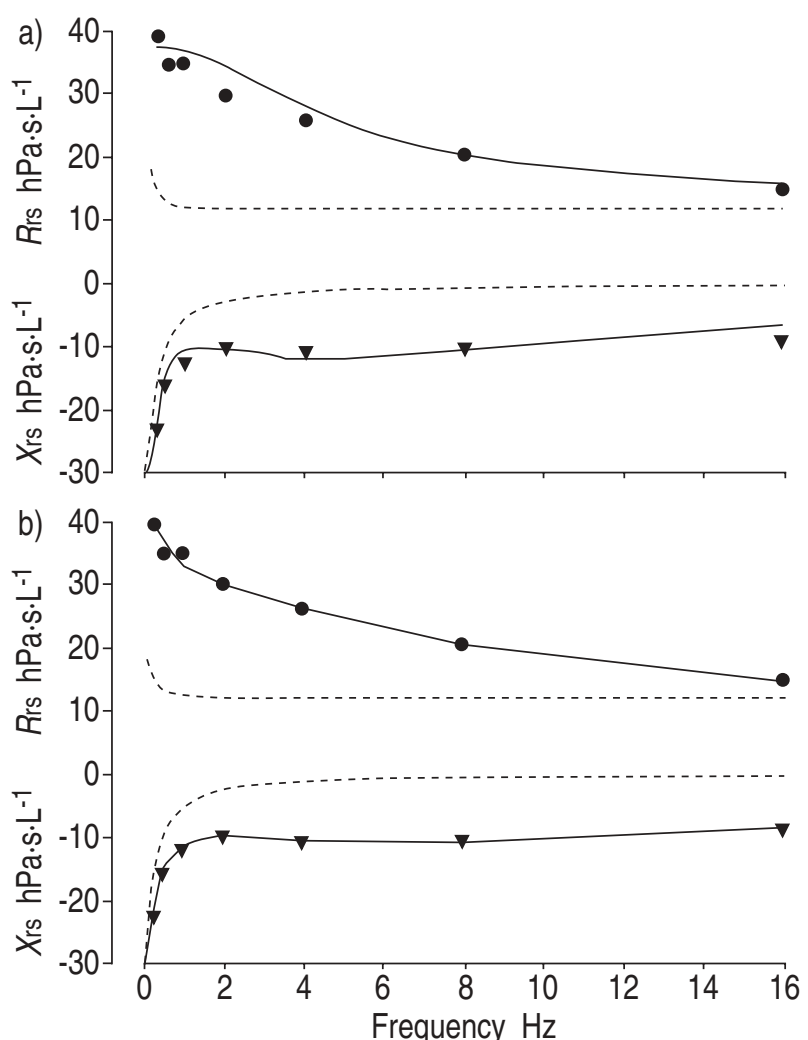

Fig. 2. - Example of the respiratory resistance $(R \mathrm{rs} ; \bullet)$ and reactance $(\mathrm{Xrs} ; \mathbf{v})$ measured by the forced oscillation technique in patient no. 1. a) Solid lines correspond to fitting the equivalent models $\mathrm{A}, \mathrm{B}$ or $\mathrm{C}$ in figure $1 . \mathrm{b}$ ) Solid lines correspond to fitting model D in figure 1. Dashed lines in a) and b) correspond to respiratory resistance $R \mathrm{rs} *$ and reactance $X \mathrm{rs} *$ derived from the occlusion technique data in this patient. 

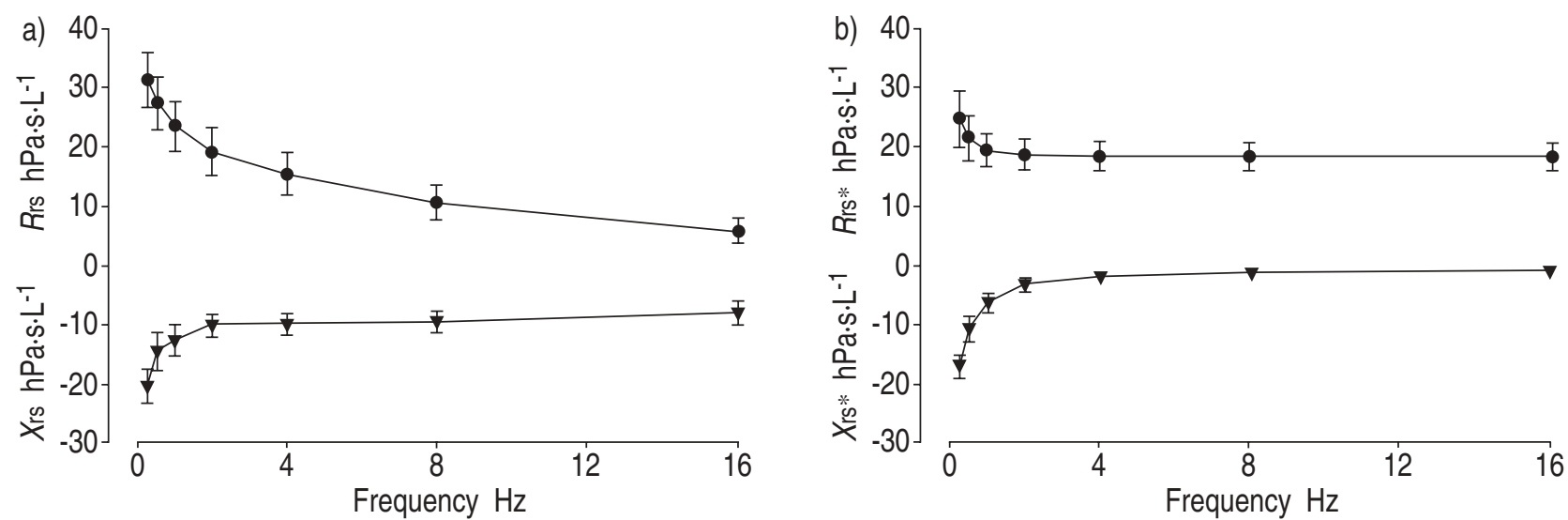

Fig. 3. - a) Respiratory resistance $(R \mathrm{rs} ; \bullet)$ and reactance $(X \mathrm{rs} ; \boldsymbol{\nabla})$ measured by the forced oscillation technique. b) Rrs* $(\bullet)$ and $X \mathrm{rs} *(\boldsymbol{\nabla})$ derived from the airway occlusion technique data. Values are shown as mean \pm SE.

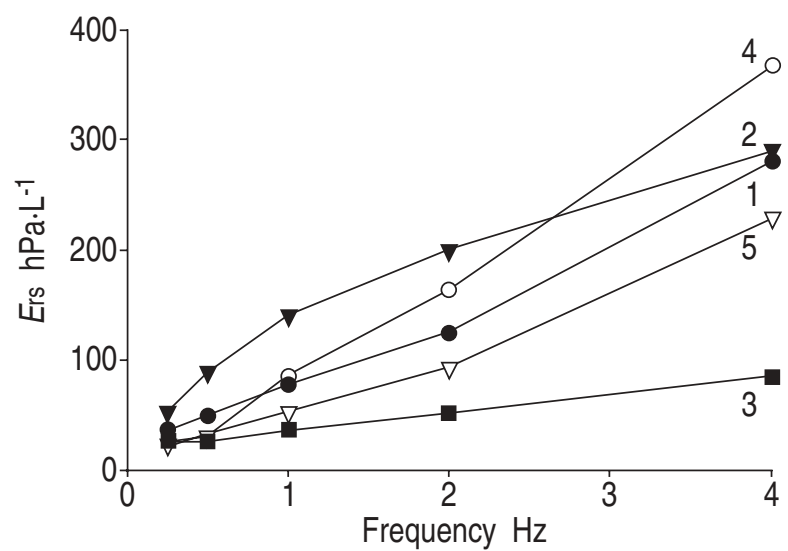

Fig. 4. - Frequency dependance of respiratory elastance (Ers) measured by forced oscillation technique in the five patients with chronic obstructive pulmonary disease. Labels indicate the patient number.

the parameters shown in table 2 . The quality of the fit achieved $(\varepsilon)$ is shown in table 2 and is illustrated in the representative example of figure $2 \mathrm{a}$. The use of the more complex model D to fit the $R$ rs and $X$ rs measured by FOT resulted in the parameter values shown in table 3 . This model was able to fit the data better than models A, B and $\mathrm{C}$ : on average, the fitting error $\varepsilon$ decreased markedly from $2.35 \mathrm{hPa} \cdot \mathrm{s} \cdot \mathrm{L}^{-1}$ (table 2 , fig. 2a) to $0.83 \mathrm{hPa} \cdot \mathrm{s} \cdot \mathrm{L}^{-1}$ (table 3 , fig. 2b).
Table 3. - Resistances and elastances derived by fitting model $D$ of figure 1 to forced oscillation technique data

\begin{tabular}{lccrcrrc}
\hline Patient No. & $\varepsilon$ & \multicolumn{1}{c}{$R_{\mathrm{c}}$} & \multicolumn{1}{c}{$E_{\mathrm{sh}}$} & $R_{\mathrm{p}}+R 1$ & $E_{1}$ & \multicolumn{1}{c}{$R 2$} & \multicolumn{1}{c}{$E 2$} \\
\hline 1 & 1.02 & 10.6 & 1040 & 22.1 & 29.8 & 9.5 & 40.9 \\
2 & 0.53 & 2.14 & 374 & 29.5 & 38.2 & 20.4 & 119 \\
3 & 0.64 & 0.0 & 875 & 10.7 & 29.8 & 36.5 & 25.5 \\
4 & 1.57 & 0.0 & 1700 & 32.0 & 22.7 & 9.8 & 72.0 \\
5 & 0.37 & 0.0 & 594 & 17.8 & 15.4 & 6.4 & 25.7 \\
\hline Mean & 0.83 & 2.55 & 917 & 22.4 & 27.2 & 16.5 & 35.2 \\
SD & 0.48 & 4.60 & 507 & 8.7 & 8.6 & 12.4 & 23.0
\end{tabular}

Resistances are in $\mathrm{hPa} \cdot \mathrm{s} \cdot \mathrm{L}^{-1}$ and elastances in $\mathrm{hPa} \cdot \mathrm{L}^{-1} \cdot \varepsilon$ (in $\left.\mathrm{hPa} \cdot \mathrm{s} \cdot \mathrm{L}^{-1}\right)$ : fitting error. See figure 1 for definitions of resistances and reactances.

The values of the resistances $(R \min , R \max )$ and elastances $\left(E_{\text {st }}, \Delta E\right)$ describing the end-inspiratory occlusion manoeuvre are shown in table 4 . $R$ max was systematically higher than $R \min$ and on average their difference $(\Delta R)$, which is an indirect index of the frequency dependence of resistance, was considerable: $\Delta R=10.0 \mathrm{hPa} \cdot \mathrm{s} \cdot \mathrm{L}^{-1}$ (35\% of $R \max ) . \Delta E$ was systematically positive and on average was $\Delta E=8.0 \mathrm{hPa} \cdot \mathrm{L}^{-1}$ ( $44 \%$ of $\left.E \mathrm{st}\right)$. The time constant $(\tau)$ corresponding to the slow decrease in pressure after the airway occlusion was in the order of $1 \mathrm{~s}(0.76 \pm 0.25 \mathrm{~s})$. The parameters of models A, B and C computed from the occlusion data are shown in table 5. Rrs* and $X \mathrm{rs} *$ corresponding to the models (A, B and C) used to interpret the occlusion manoeuvres in patient no. 1 are shown in figure

Table 2. - Resistances and elastances derived by fitting models A, B and C of figure 1 to forced oscillation technique data

\begin{tabular}{|c|c|c|c|c|c|c|c|c|c|c|c|c|c|}
\hline \multirow[b]{3}{*}{ Patient No. } & \multirow[b]{3}{*}{$\varepsilon$} & \multicolumn{12}{|c|}{ Model } \\
\hline & & \multicolumn{4}{|c|}{ A } & \multicolumn{4}{|c|}{ B } & \multicolumn{4}{|c|}{$\mathrm{C}$} \\
\hline & & $R \mathrm{c}$ & $E_{\text {sh }}$ & $R \mathrm{p}$ & $E \mathrm{t}$ & $R 1$ & $E 1$ & $R 2$ & $E_{2}$ & $R \mathrm{a}$ & $E$ a & $R \mathrm{~b}$ & $E \mathrm{~b}$ \\
\hline 1 & 2.59 & 13.6 & 702 & 24.0 & 42.2 & 13.6 & 39.8 & 21.4 & 662 & 23.3 & 1814 & 36.5 & 40.7 \\
\hline 2 & 1.99 & 3.9 & 264 & 51.2 & 43.3 & 3.9 & 37.2 & 37.8 & 227 & 5.7 & 313 & 53.6 & 42.2 \\
\hline 3 & 1.63 & 0.4 & 850 & 11.7 & 26.2 & 0.4 & 25.4 & 11.0 & 825 & 0.4 & 911 & 12.1 & 26.1 \\
\hline 4 & 3.78 & 3.3 & 1305 & 35.2 & 25.4 & 3.3 & 24.9 & 33.9 & 1280 & 3.7 & 1566 & 38.4 & 25.3 \\
\hline 5 & 1.76 & 0.8 & 496 & 20.0 & 21.9 & 0.8 & 21.0 & 18.3 & 475 & 0.9 & 538 & 20.7 & 21.8 \\
\hline$\overline{\text { Mean }}$ & 2.35 & 4.4 & 723 & 28.4 & 31.8 & 4.4 & 29.7 & 24.5 & 694 & 6.8 & 1029 & 32.3 & 31.2 \\
\hline SD & 0.88 & 5.4 & 393 & 15.3 & 10.1 & 5.4 & 8.3 & 11.1 & 396 & 9.5 & 647 & 16.2 & 9.5 \\
\hline
\end{tabular}

Resistances are in hPa $\cdot \mathrm{s} \cdot \mathrm{L}^{-1}$ and elastances in $\mathrm{hPa} \cdot \mathrm{L}^{-1} \cdot \varepsilon$ (in hPa$\left.\cdot \mathrm{s} \cdot \mathrm{L}-1\right)$ : fitting error. See figure 1 for definitions of resistances and reactances. 
Table 4. - Resistances, elastances and time constant from the end-inspiratory occlusion manoeuvres

\begin{tabular}{lccccc}
\hline $\begin{array}{l}\text { Patient } \\
\text { No. }\end{array}$ & $\begin{array}{c}R \min \\
\mathrm{hPa} \cdot \mathrm{s} \cdot \mathrm{L}^{-1}\end{array}$ & $\begin{array}{c}R \max \\
\mathrm{hPa} \cdot \mathrm{s} \cdot \mathrm{L}^{-1}\end{array}$ & $\begin{array}{c}E_{\mathrm{st}} \\
\mathrm{hPa} \cdot \mathrm{L}^{-1}\end{array}$ & $\begin{array}{c}\Delta E \\
\mathrm{hPa} \cdot \mathrm{L}^{-1}\end{array}$ & $\begin{array}{c}\tau \\
\mathrm{s}\end{array}$ \\
\hline 1 & 11.7 & 18.1 & 22.7 & 5.0 & 0.77 \\
2 & 23.9 & 50.0 & 21.1 & 19.0 & 0.34 \\
3 & 12.6 & 19.6 & 12.2 & 7.4 & 0.98 \\
4 & 20.2 & 25.7 & 18.4 & 4.8 & 0.91 \\
5 & 23.8 & 28.8 & 16.1 & 3.7 & 0.81 \\
\hline Mean & 18.4 & 28.4 & 18.1 & 8.0 & 0.76 \\
SD & 5.9 & 12.8 & 4.2 & 6.3 & 0.25 \\
\hline
\end{tabular}

$R$ min: minimum resistance; $R \max$ : maximum resistance; $E$ st: static elastance; $\Delta E$ : change in elastance; $\tau$ : time constant.

2 (dashed lines). The mean \pm SE of $R \mathrm{rs} *$ and $X \mathrm{rs} *$ corresponding to the models (A, B and $\mathrm{C}$ ) used to interpret the occlusion manoeuvres are shown in figure $3 \mathrm{~b}$. On average, $R \mathrm{rs} *$ decreased markedly with frequency from $R \max$ at zero frequency to $R \min$ at $\sim 1 \mathrm{~Hz}$ and remained constant at higher frequencies. $X_{\mathrm{rs}} *$ exhibited the frequency-dependent pattern characteristic of an effective elastance which rapidly increased from the static value $E 1$ at zero frequency to about $E 2$ at $\sim 1 \mathrm{~Hz}$ and then remained constant at this value at higher frequencies.

A considerable discrepancy was found when comparing the frequency dependence of $R \mathrm{rs}$ and $X \mathrm{rs}$ measured by FOT (fig. 3a) and that of $R \mathrm{rs} *$ and $X \mathrm{rs} *$ derived from the interpretation of the occlusion manoeuvres with models A, B or C (fig. 3b). At $0.25 \mathrm{~Hz}$, the lowest frequency measured by FOT, Rrs and $X$ rs showed no significant differences (paired t-test at level $\mathrm{p}=0.05$ ) with $R \mathrm{rs} *$ and $X \mathrm{rs} *$, respectively: $R \mathrm{rs}=31.3 \pm 5.2, \quad R \mathrm{rs} *=24.9 \pm 5.3, X \mathrm{rs}=-20.3 \pm$ $3.5, X \mathrm{rs} *=-16.9 \pm 2.2$ (in hPa.s.L-1; mean $\pm \mathrm{sE}$ ). Nevertheless, $R \mathrm{rs} *$ and $X \mathrm{rs} *$ differed markedly from $R \mathrm{rs}$ and $X \mathrm{rs}$ at higher frequencies (above $\sim 1 \mathrm{~Hz}$ ). Moreover, the effective elastance Ers measured by FOT (fig. 4) progressively increased with frequency while respiratory system elastance corresponding to the fitted models A, B and C increased up to $\sim 1 \mathrm{~Hz}$ and from then on remained almost constant. Similarly, the parameters obtained when using models A, B or C to interpret FOT data (table 2) and occlusion technique data (table 5) were markedly different. This is clearly indicated by the characteristic time constant of the models: $R \mathrm{p} /\left(E_{\mathrm{sh}}+E_{\mathrm{t}}\right), R 2 / E_{2}$ and $(R \mathrm{a}+R \mathrm{~b}) /\left(E_{\mathrm{a}}+E \mathrm{~b}\right)$ for models A, B and C, respectively [21]. Data from FOT resulted in parameter sets accounting for a time constant of $\sim 35 \mathrm{~ms}$, whereas the analysis of the occlusion manoeuvre data re- sulted in parameter sets for models $\mathrm{A}, \mathrm{B}$ and $\mathrm{C}$ accounting for a much greater time constant of $\sim 0.8 \mathrm{~s}$.

\section{Discussion}

The first result obtained when applying FOT to mechanically ventilated COPD patients over a frequency band extending down to spontaneous breathing rates was that $R \mathrm{rs}$ and $X \mathrm{rs}$ exhibited a marked frequency dependence from $0.25-16 \mathrm{~Hz}$. The second finding was that interpretation of FOT and occlusion technique data with the most common simple models used in the literature (A, B and $\mathrm{C}$ in fig. 1) provided conflicting results in terms of the parameter values (tables 2 and 5) and the frequency dependence of resistance and reactance (fig. 3). Such a result contrasts with data previously obtained in healthy dogs $[16,24]$ and in a series of patients including a minority with COPD [9], where both techniques provided consistent results. A possible reason for these results could be that simple models such as A, B and C featuring only one mechanism, i.e. airway wall shunting $\mathrm{A}$, tissue viscoelasticity $\mathrm{B}$, parallel inhomogeneity $\mathrm{C}$, are not adequate to account for the dynamic response $(0.25-16 \mathrm{~Hz})$ of the respiratory system in mechanically ventilated COPD patients. In fact, a model (D in fig. 1) including two mechanisms, i.e. airway wall shunting and tissue viscoelasticity, was better able to reproduce the frequency dependence of $R$ rs and $X$ rs measured by FOT (fig. 2).

To our knowledge, this is the first study in which FOT has been applied in mechanically ventilated COPD patients for a frequency band extending down to spontaneous breathing frequencies $(0.25 \mathrm{~Hz})$. On average, $R$ rs (fig. 3) exhibited considerably high values and a marked negative frequency dependence, which contrasts with those (6.2 $\mathrm{hPa} \cdot \mathrm{s} \cdot \mathrm{L}^{-1}$ at $0.25 \mathrm{~Hz}$ and $1.8 \mathrm{hPa} \cdot \mathrm{s} \cdot \mathrm{L}^{-1}$ at $16 \mathrm{~Hz}$ ) reported for the same frequency band in healthy, anaesthetized, paralysed patients [25]. The most remarkable feature of $X$ rs (fig. 3) was that it always remained negative and therefore no patient exhibited the resonant frequency within the investigated frequency band, which is also in contrast to the findings in healthy patients [25]. The only FOT data available on mechanically ventilated patients correspond to frequencies above $4-5 \mathrm{~Hz}[7,9]$. BeYDon et al. [9] reported a negative frequency dependence of $R \mathrm{rs}(35 \% \mathrm{dec}-$ rease from $4-16 \mathrm{~Hz}$ ), which was smaller than that found in the present study (65\% decrease) between these two relatively high frequencies. Nevertheless, data from these

Table 5. - Resistances and elastances derived by fitting models A, B and C of figure 1 to the occlusion manoeuvres data (table 4)

\begin{tabular}{|c|c|c|c|c|c|c|c|c|c|c|c|c|}
\hline \multirow[b]{3}{*}{ Patient No. } & \multicolumn{12}{|c|}{ Model } \\
\hline & \multicolumn{4}{|c|}{$\mathrm{A}$} & \multicolumn{4}{|c|}{$\mathrm{B}$} & \multicolumn{4}{|c|}{$\mathrm{C}$} \\
\hline & $R \mathrm{c}$ & $E_{\text {sh }}$ & $R \mathrm{p}$ & $E_{\mathrm{t}}$ & $R 1$ & $E 2$ & $R 1$ & $E_{2}$ & $R \mathrm{a}$ & $E_{\mathrm{a}}$ & $R \mathrm{~b}$ & $E \mathrm{~b}$ \\
\hline 1 & 11.7 & 33.0 & 81.1 & 72.7 & 11.7 & 22.7 & 7.9 & 10.3 & 83.6 & 114 & 25.4 & 28.4 \\
\hline 2 & 23.9 & 98.6 & 43.1 & 26.8 & 23.9 & 21.1 & 26.6 & 77.5 & 53.3 & 302 & 58.1 & 22.7 \\
\hline 3 & 12.6 & 22.7 & 52.8 & 26.4 & 12.6 & 12.2 & 11.3 & 10.5 & 51.6 & 64.1 & 33.6 & 15.1 \\
\hline 4 & 20.2 & 26.8 & 77.4 & 58.7 & 20.2 & 18.4 & 7.6 & 8.4 & 126 & 156 & 33.5 & 20.9 \\
\hline 5 & 23.8 & 23.6 & 60.4 & 50.7 & 23.8 & 16.1 & 6.1 & 7.5 & 159 & 220 & 33.8 & 17.4 \\
\hline Mean & 18.4 & 40.9 & 62.9 & 47.1 & 18.4 & 18.1 & 11.9 & 22.8 & 94.7 & 171 & 36.9 & 20.9 \\
\hline SD & 5.9 & 32.5 & 16.1 & 20.2 & 5.9 & 4.2 & 8.4 & 30.6 & 44.7 & 92.7 & 12.4 & 5.1 \\
\hline
\end{tabular}

Resistances are in hPa $\cdot \mathrm{s} \cdot \mathrm{L}^{-1}$ and elastances in $\mathrm{hPa} \cdot \mathrm{L}^{-1}$. See figure 1 for definitions of resistances and reactances. 
authors were obtained from a population including few COPD patients (3 out of 16). By contrast, PesLin et al. [7] reported data from a population of mechanically ventilated patients, most of whom (11 out of 17) suffered from COPD. These authors analysed respiratory mechanics at frequencies above $5 \mathrm{~Hz}$ during different phases of the ventilation cycle and reported a frequency dependence of $R$ rs and $X$ rs consistent with that found in the patients in this study [7]. The results obtained when using model A (table 2) indicate that the peripheral resistance $R \mathrm{p}$ accounted for $87 \%$ of the total resistance $(R \mathrm{c}+R \mathrm{p})$ and the mean elas-tance $E$ sh partitioning central and peripheral resistances corresponded to a compliance of $1.4 \mathrm{~mL} \cdot \mathrm{hPa}^{-1}$. This value was close to those reported by PEsLiN et al. [7] $\left(0.64-2.56 \mathrm{~mL} \cdot \mathrm{hPa}^{-1}\right)$ when using the same model to analyse FOT data in ventilated COPD patients from 5-20 Hz. Models B and C, which attribute the frequency dependence of $R$ rs to tissue viscoelasticity or to parallel inhomogeneity, respectively, resulted in a much lower time constant $(\sim 35 \mathrm{~ms})$ than expected for these two mechanisms, which seem to determine the frequency dependence of $R$ rs mainly at the lowest frequencies $[19,20]$. The fact that the frequency dependence of $R$ rs (fig. 3a) and $E$ rs (fig. 4) extends to frequencies $>2 \mathrm{~Hz}$ suggests that the role played by airway wall shunting is not negligible [20].

The results obtained by means of the end-inspiratory AOT (table 4) were in keeping with the few data on COPD patients available in the literature. Resistances and elastances reported by POLESE et al. [5] were smaller than those in the present patients (by $\sim 16 \%$ in $E$ st, and $\Delta E$ and by $\sim 42 \%$ in $R \min$ and $R \max$ ), probably owing to a greater severity in the obstructive pathology and/or a higher degree of hyperinflation in the patients in this study, as suggested by the fact that the measured PEEPi (table 1) was $44 \%$ greater than the value reported by POLESE et al. [5]. However, a remarkable agreement was found in the ratios $R \min / R \max (0.64$ from our data and 0.65 in [5]) and (Est+ $\Delta E) / E$ st $(0.70$ both from our data and in [5]), which are representative of the frequency dependence of the respiratory system. The time constant $\tau \sim 0.8 \mathrm{~s}$ found in this study, which could not be compared with data on COPD patients since it was not reported in [5], was of the same order of magnitude, although smaller than in normal subjects $(\sim 1.3 \mathrm{~s} \mathrm{[11]})$. As expected, interpretation of the occlusion technique data with model $\mathrm{B}$, which is commonly employed with this technique, provides tissue parameters (table 5) consistent with the values reported previously. From the results obtained by using model A, shunt elastance $\left(E_{\mathrm{sh}}\right)$ would be similar to tissue elastance $\left(E_{\mathrm{t}}\right)$ (table 5 ). According to the parameters for model $\mathrm{C}$, the two parallel compartments would be characterized by time constants with a ratio, $(R \mathrm{a} / E \mathrm{a}) /(R \mathrm{~b} / E \mathrm{~b})$, of about $1 / 3$. The more complex model $\mathrm{D}$ was not fitted to the occlusion data since the model interpretation of these data is limited by the relatively narrow effective band width of the signals recorded. Indeed, the occlusion technique, which is a forced excitation with a pulse of flow of $\sim 1 \mathrm{~s}$ of duration, has its main frequency components restricted to the lowest frequencies (d.c. $\sim 2 \mathrm{~Hz}$ ). Moreover, the actual closure time of the valve limits the practical applicability of the technique for detecting short time constants and, hence, reduces the reliability of parameter estimates when analysing high frequencies [26]. In this regard, it should be noted that the occlusion data obtained in this study, and in others in the literature where the interruption is per- formed with the valve of a conventional ventilator, are affected by the finite closure time of the valve. Consequently, owing to the practical limitations arising from occluding the airway with the valve of a conventional ventilator, this technique does not allow an exploration of respiratory system mechanics for a frequency band as wide as the FOT. However, the use of a more rapidly closing valve could improve the high frequency sensitivity of the occlusion technique.

The FOT data measured from $0.25-16 \mathrm{~Hz}$ and their model interpretation suggest that simple models such as A, B or C (fig. 1), which are associated with a unique time constant, are not able to describe adequately the frequency dependence of $R \mathrm{rs}$ and $X \mathrm{rs}$ in ventilated COPD patients. By contrast, a model (D in fig. 1) featuring more than one mechanism, i.e. airway wall shunt and tissue viscoelasticity, significantly improved the quality of fitting (table 3, fig. 2). This model suggested that, on the one hand, the viscoelastic tissue compartment was characterized by a relatively long time constant $(R 2 / E 2$ was $0.45 \mathrm{~s}$ on average, table 3 ) similar to that obtained from the occlusion technique (table 5). On the other hand, airway wall shunt was characterized by a much shorter time constant $(\sim(R 1+R \mathrm{p}) /$ $E$ sh; on average $\sim 30 \mathrm{~ms}$; table 5 ) explaining the frequency dependence observed at high frequencies. Nevertheless, it should be noted that the fact that model $\mathrm{D}$ provided a reasonable description of $R \mathrm{rs}$ and $X$ rs does not exclude the suitability of other models allowing for more than one time constant, e.g. models that, as expected in ventilated COPD patients, include parallel inhomogeneities [19, 20] in addition to airway wall shunting and tissue viscoelasticity. Consequently, the FOT applied for a frequency band such as the one in this work $(0.25-16 \mathrm{~Hz})$, which is wide enough to cover several time constants, is a potentially useful tool for exploring respiratory system properties in artificially ventilated COPD patients. Comparing the results of the FOT and AOT is of interest since the respiratory system is subjected to considerably different volume ex-cursions with the two techniques. Therefore, the results obtained from tidal volume excursions (AOT) and from small-amplitude FOT measurements at end-inspiratory and end-expiratory pauses could provide information about nonlinearities and may be useful in elucidating the mechanisms involved in inhomogeneous airway constriction $[27,28]$.

The potential clinical interest of the above results and modelling is enhanced by the fact that the two techniques are noninvasive and easily applicable with minimal disturbance of the artificial ventilation. On the one hand, the airway occlusion technique has been extensively used in the literature to analyse respiratory mechanics in ventilated healthy subjects and in patients with different pathologies. On the other hand, the interest in the forced oscillation technique for monitoring respiratory mechanics in intubated patients has recently been pointed out [29]. Its feasibility has been facilitated by the solution of the main methodological problems concerning this technique (generators capable of operating in parallel with the ventilator $[7,8,10]$ and ways of overcoming the nonlinearity of the endotracheal tube [7,30-32]. An additional feature of the forced oscillation technique is that it may provide automatic and on-line assessment of respiratory mechanics over the breathing cycle [7,33-35]. As the forced oscillation technique allows practical assessment of respiratory mechanics over a frequency band wider than the occlusion 
technique, its application in ventilated patients with chronic obstructive pulmonary disease may provide data for monitoring the patient's status and progress and, therefore, may be useful in optimizing the ventilator settings.

Acknowledgements: The authors wish to thank M.A. Rodríguez for his technical assistance.

\section{References}

1. Slutsky AS. Mechanical ventilation. ACCP consensus conference. Chest 1993; 104: 1833-1859.

2. Burke WC, Crooke PS III, Marcy TW, Adams AB, Marini JJ. Comparison of mathematical and mechanical models of pressure-controlled ventilation. J Appl Physiol 1993; 74: 922-933.

3. Marini JJ, Crooke PS III. A general mathematical model for respiratory dynamics relevant to the clinical setting. Am Rev Respir Dis 1993; 147: 14-24.

4. Peslin R, Felicio da Silva J, Chabot F, Duvivier C. Respiratory mechanics studied by multiple linear regression in unsedated ventilated patients. Eur Respir J 1992; 5: 871878.

5. Polese G, Rossi A, Appendini L, Brandi G, Bates JHT, Brandolose R. Partitioning of respiratory mechanics in mechanically ventilated patients. J Appl Physiol 1991; 71: 2425-2433.

6. Similowski T, Bates JHT. Two-compartment modelling of respiratory system mechanics at low frequencies: gas redistribution or tissue rheology? Eur Respir J 1991; 4: 353-358.

7. Peslin R, Felicio da Silva J, Duvivier C, Chabot F. Respiratory mechanics studied by forced oscillations during artificial ventilation. Eur Respir J 1993; 6: 772-784.

8. Farré R, Ferrer M, Rotger M, Navajas D. Servocontrolled generator to measure respiratory impedance from 0.25 to $26 \mathrm{~Hz}$ in ventilated patients at different PEEP levels. Eur Respir J 1995; 8: 1222-1227.

9. Beydon L, Malassiné P, Lorino AM, et al. Respiratory resistance by end-inspiratory occlusion and forced oscillations in intubated patients. J Appl Physiol 1996; 80: $1105-1111$.

10. Navajas D, Farré R, Rotger M, Torres A. Monitoring respiratory impedance by forced oscillation in mechanically ventilated patients. Eur Respir Rev 1994; 4: 216-218.

11. D'Angelo E, Calderini E, Torri G, Robatto FM, Bono D, Milic-Emili J. Respiratory mechanics in anesthetized paralyzed humans: effects of flow, volume and time. $J$ Appl Physiol 1989; 67: 2556-2564.

12. D'Angelo E, Robatto FM, Calderini E, et al. Pulmonary and chest wall mechanics in anesthetized paralyzed humans. J Appl Physiol 1991; 70: 2602-2610.

13. Eissa NT, Ranieri VM, Corbeil C, et al. Analysis of behavior of the respiratory system in ARDS patients: effect of flow, volume, and time. J Appl Physiol 1991; 70: 2719-2729.

14. Bates JHT, Hunter IW, Sly PD, Okubo S, Filiatrault S, Milic-Emili J. Effect of valve closure time on the determination of respiratory resistance by flow interruption. Med Biol Eng Comput 1987; 25: 136-140.

15. Mead J. Contribution of compliance of airways to frequency dependence behaviour of lung. J Appl Physiol 1969; 26: 670-673.

16. Bates JHT, Brown, KA, Kochi T. Respiratory mechanics in the normal dog determined by expiratory flow interruption. J Appl Physiol 1989; 67: 2276-2285.

17. Otis $\mathrm{AB}$, McKerrow CB, Bartlett RA, et al. Mechanical factors in distribution of pulmonary ventilation. $J$ Appl Physiol 1956; 8: 427-443.

18. Bates JHT. Stochastic model of the pulmonary airway tree and its implication for bronchial responsiveness. $J$ Appl Physiol 1993; 75: 2493-2499.

19. Lutchen KR, Greenstein JL, Suki B. How inhomogeneities and airway walls affect frequency dependence and separation of airway and tissue properties. J Appl Physiol 1996; 80: 1696-1707.

20. Lutchen KR, Gillis H. Relationship between heterogeneous changes in airway morphometry and lung resistance and elastance. J Appl Physiol 1997; 83: 1192-1201.

21. Lorino AM, Lorino H, Harf A. A synthesis of the Otis, Mead, and Mount mechanical respiratory models. Respir Physiol 1994; 97: 123-133.

22. Bates JHT, Rossi A, Milic-Emili, J. Analysis of the behavior of the respiratory system with constant inspiratory flow. J Appl Physiol 1985; 58: 1840-1848.

23. Bates JHT, Baconnier P, Milic-Emili, J. A theoretical analysis of interrupter technique for measuring respiratory mechanics. J Appl Physiol 1988; 64: 2204-2214.

24. Bates JHT, Daroczy B, Hantos Z. A comparison of interrupter and forced oscillation measurements of respiratory resistance in the dog. J Appl Physiol 1992; 72: 46-52.

25. Navajas D, Farré R, Canet J, Rotger M, Sanchis J. Respiratory input impedance in anesthetized paralysed patients. J Appl Physiol 1990; 69: 1372-1379.

26. Lutchen KR, Jackson AC. Reliability of parameter estima-tes from models applied to respiratory impedance data. J Appl Physiol 1987; 62: 403-413.

27. Suki B, Yuan H, Zheng Q, Lutchen KR. Partitioning of lung tissue response and inhomogeneous airway constriction at the airway opening. J Appl Physiol 1997; 82: 13491359.

28. Bates JHT, Schuessler TF, Dolman C, Eidelman DH. Temporal dynamics of acute isovolume bronchoconstriction in the rat. J Appl Physiol 1997; 82: 55-62.

29. Van de Woestijne KP. The forced oscillation technique in intubated, mechanically ventilated patients. Eur Respir J 1993; 6: 767-769.

30. Navajas D, Farré R, Rotger M, Canet J. Recording pressure at the distal end of the endotracheal tube to measure respiratory impedance. Eur Respir J 1989; 2: 178-184.

31. Lorino AM, Beydon L, Mariette C, Dahan E, Lorino H. A new correction technique for measuring respiratory impedance through an endotracheal tube. Eur Respir J 1996; 9: 1079-1086.

32. Navalesi P, Hernandez P, Laporta D, et al. Influence of site of tracheal pressure measurement on in situ estimation of endotracheal tube resistance. J Appl Physiol 1995; 58: $1840-1848$.

33. Vassiliou M, Peslin R, Saunier C, Duvivier C. Expiratory flow limitation during mechanical ventilation detected by the forced oscillation method. Eur Respir J 1996; 9: 779786.

34. Farré R, Peslin R, Rotger M, Navajas D. Inspiratory dynamic obstruction detected by forced oscillation during CPAP. A model study. Am J Respir Crit Care Med 1997; 155: 952-956.

35. Farré R, Rotger M, Montserrat JM, Navajas D. A system to generate simultaneous forced oscillation and continuous positive airway pressure. Eur Respir J 1997; 10: 13491353. 